\title{
Castleman disease
}

INSERM

\section{Source}

INSERM. (1999). Orphanet: an online rare disease and orphan drug data base. Castleman disease. ORPHA:160

Castleman disease (CD) is a benign lymphoproliferative disorder that may present as a localized or multicentric form (see these terms). The clinical manifestations are heterogeneous, ranging from asymptomatic discrete lymphadenopathy to recurrent episodes of diffuse lymphadenopathy with severe systemic symptoms. 